\title{
First-Known Hypnopompic Hallucination Occurring In-Hospital: Case Report
}

Paul Ballas D.O. (PGY2)

PaulBallas@yahoo.com

Follow this and additional works at: https://jdc.jefferson.edu/jeffjpsychiatry

Part of the Psychiatry Commons

Let us know how access to this document benefits you

\section{Recommended Citation}

Ballas, Paul D.O. (PGY2) (2006) "First-Known Hypnopompic Hallucination Occurring In-Hospital: Case Report," Jefferson Journal of Psychiatry. Vol. 20 : Iss. 1 , Article 6.

DOI: https://doi.org/10.29046/JJP.020.1.005

Available at: https://jdc.jefferson.edu/jeffjpsychiatry/vol20/iss1/6

This Article is brought to you for free and open access by the Jefferson Digital Commons. The Jefferson Digital Commons is a service of Thomas Jefferson University's Center for Teaching and Learning (CTL). The Commons is a showcase for Jefferson books and journals, peer-reviewed scholarly publications, unique historical collections from the University archives, and teaching tools. The Jefferson Digital Commons allows researchers and interested readers anywhere in the world to learn about and keep up to date with Jefferson scholarship. This article has been accepted for inclusion in Jefferson Journal of Psychiatry by an authorized administrator of the Jefferson Digital Commons. For more information, please contact: JeffersonDigitalCommons@jefferson.edu. 


\section{First-Known Hypnopompic Hallucination Occurring In-Hospital: Case Report}

Paul Ballas, D.O. (PGY2)

\section{ABSTRACT}

Despite the high prevalence of hypnopompic hallucinations in the community, to our knowledge there are no reports that have been published in the English literature of these phenomenon observed by staff in the hospital setting. Psychiatric or neurological evaluation often ensues if a patient reports hallucinations in other circumstances, but when they are reported in connection with sleep, further evaluation is rarely performed because such events are common in the general populace. Our report emphasizes the distinction between hypnopompic and hypnagogic hallucination as an ongoing feature of life that someone is aware of, which we believe to be the case for normal persons who have them, and a similar hallucination occurring for the first time in someone who is unaware of it, at least unable to remember it. In the latter instance, we suggest careful interview for symptoms of a sleep disorder.

Hypnagogic (prior to sleep onset) and hypnopompic (upon arousal from sleep) hallucinations are both phenomena that occur in normal people and symptoms that are characteristic of narcolepsy $(1,2)$. They are a common occurrence, experienced by almost everyone at least once and have also been shown to be associated with the use or withdrawal from certain medications, specifically, tricyclic antidepressants, opiates, and donepezil (3-5). Although hypnopompic and hypnagogic hallucinations are generally considered to be normal phenomenon, they have increased incidence in several psychiatric and neurologic disorders (6). One study of over 14,000 subjects revealed that people with anxiety, depression, or bipolar affective disorder have a two-fold increase in experiencing hypnopompic or hypnagogic hallucinations at least once weekly. The same study showed that people with adjustment disorders have a 1.5- fold increase in experiencing these phenomenon at least once weekly (6-8). The notion that such phenomena are normal may be part of the reason behind the wide variation in the literature with regard to their lifetime incidence (hypnopompic 6-13\%, hypnagogic 25-38\%) (4, 9-11). Over 50 percent of people who experience them have no 
appreciable physical disorder, substance-abuse disorder, sleep disorder, or other psychiatric disorder (12).

\section{CASE REPORT}

F.R. is a 41-year-old African American woman who had been admitted to the medical service after one day of shortness of breath and two weeks of dull chest pain, night sweats, and a non-purulent productive cough. She had recently completed a 3-week corticosteroid taper and a full course of azithromycin for an upper respiratory infection. The patient had a long history of asthma, hypertension, and gastroesophageal reflux. She also had suffered from Grave's disease in the distant past; hypothyroidism developed later on but has been corrected with thyroxin. The patient was compliant with her outpatient medications: levothyroxine, hydrochloro-thiazide, montelukast, Protonix, fluticasone/salmeterol, continuous home oxygen, multivitamin, and inhaled albuterol. She had no personal or family history of neurologic or psychiatric disorders.

These medications were maintained, and intravenous corticosteroid was initiated. Albuterol was given every 2 hours by nebulizer. Part of the protocol at this hospital for someone receiving nebulizer treatments so often is that physicianreassessment must take place before each treatment. On the first night, after approximately four hours of sleep, the patient was awakened for the second time; she promptly sat up in bed, looked at her right arm, and yelled, "There's blood all over my arm!” The resident physician (one of the authors, P.B.) examined her arm and saw only a clean IV placement. He informed the patient of this, but she looked back at her arm and proffered it again saying "Look, can't you see all this blood?" Again the physician reassured her that there was nothing there, the patient sat still and allowed herself to be evaluated. She showed no signs of a formal thought disorder or of delusion, and she denied any hallucination apart from feeling and seeing blood on her arm. Speech was organized normally. Neurological exam was normal. Respiration remained labored, but after the assessment she went back to sleep.

She was examined several other times over the next day and at no other time during the admission did she have any other hallucinations or exhibit any signs or symptoms of a neurologic or psychiatric disorder. When asked about the incident, the patient had no memory of the hallucinations although she did remember being awakened multiple times. When questioned about her sleep outside the hospital, the patient did not know if she snored or had apneic episodes, but did report poor 
sleep quality (frequent unintentional awakenings) and excessive daytime sleepiness. She was referred to a sleep specialist for further evaluation.

\section{DISCUSSION}

This case shows that even with no history of prior psychiatric or neurologic disorders, patients in the hospital can have quite striking hallucinations upon awakening. Given the high prevalence of hypnopompic hallucinations among normal persons, it is no surprise many clinicians tend to disregard isolated incidences such as the one described. And yet people who experience unusual sleep-related events typically have been aware of them their entire lives. For example, in adults who experience sleepwalking or sleep talking there is a high prevalence of these phenomena since childhood (13).

We believe it is reasonable to do an in-depth interview specifically for sleep disorders in every patient who experiences a hypnopompic or hypnagogic hallucination for the first time. Sleep disorders are common, debilitating conditions that often go undiagnosed, yet they increase the risk of substance abuse and psychiatric disorders $(9,10,14,15)$. If the interview turns up symptoms consistent with a sleep disorder, often a referral to a sleep specialist will be indicated.

\section{SOURCE INFORMATION}

From the Department of Psychiatry and Human Behavior, Thomas Jefferson University Hospital, Philadelphia. Direct inquiries to Dr. Ballas: PaulBallas@yahoo.com

\section{REFERENCES}

1. Zeman A, Britton T, Douglas N, Hansen A, Hicks J, Howard R, Meredith A, Smith I, Stores G, Wilson S, Zaiwalla Z. Narcolepsy and excessive daytime sleepiness. Brit Med J 2004; 329:724-8

2. Yager J, Gitlin MJ. Clinical manifestations of psychiatric disorders, pp. 987-8. In, Sadock BJ, Sadock VA (2005), eds. Kaplan \& Sadock's Comprehensive Textbook of Psychiatry. Philadelphia: Lippincott Williams \& Wilkins 
3. Cancelli I, Marcon G, and Balestrieri M. Factors associated with complex visual hallucinations during antidepressant treatment. Human Psychopharmacol 2004; 19:577-84

4. Fountain A. Visual hallucinations: a prevalence study among hospice inpatients. Palliative Med 2001; 15:19-25

5. Yorston GA, Gray R. Hypnopompic hallucinations with donepezil. J Psychopharmacol 2000; 14:303-4

6. Ohayon MM. Prevalence of hallucinations and their pathological associations in the general population. Psychiatry Res 2000; 97:153-64

7. Ohayon MM, Shapiro CM. Sleep disturbances and psychiatric disorders associated with posttraumatic stress disorder in the general population. Comprehen Psychiatry 2000; 41:469-78

8. Ohayon MM, Priest RG, Caulet M, and Guilleminault C. Hypnagogic and hypnopompic hallucinations: pathological phenomena? Brit J Psychiatry 1996; 169: 459-67

9. Breslau N, Roth T, Rosenthal L, and Andreski P. Sleep disturbance and psychiatric disorders: a longitudinal epidemiological study of young adults. Biol Psychiatry 1996; 39:411-18

10. Ford DE, Kamerow DB. Epidemiologic study of sleep disturbances and psychiatric disorders. An opportunity for prevention? JAMA 1989; 262:1479-84

11. Takata K, Inoue Y, Hazama H, Fukuma E. Night-time hypnopompic visual hallucinations related to REM sleep disorder. Psychiatry Clin Neurosci 1998; 52:207-9

12. Ohayon MM, Priest RG, Zulley J, Smirne S. The place of confusional arousals in sleep and mental disorders: findings in a general population sample of 13,057 subjects. J Nerv Mental Dis 2000; 188:340-8

13. Hublin C, Kaprio J, Partinen M, Heikkila K, Koskenvuo M. Prevalence and genetics of sleepwalking: a population-based twin study. Neurol 1997; 48:177-81

Jefferson Journal of Psychiatry, Volume 20, Number 1 
14. Simon GE, VonKorff M. Prevalence, burden, and treatment of insomnia in primary care. Am J Psychiatry 1997; 154:1417-23

15. Roth T, Ancoli-Israel S. Daytime consequences and correlates of insomnia in the United States: results of the 1991 National Sleep Foundation Survey. II. Sleep 1999; 22 (Suppl 2):S354-8 